
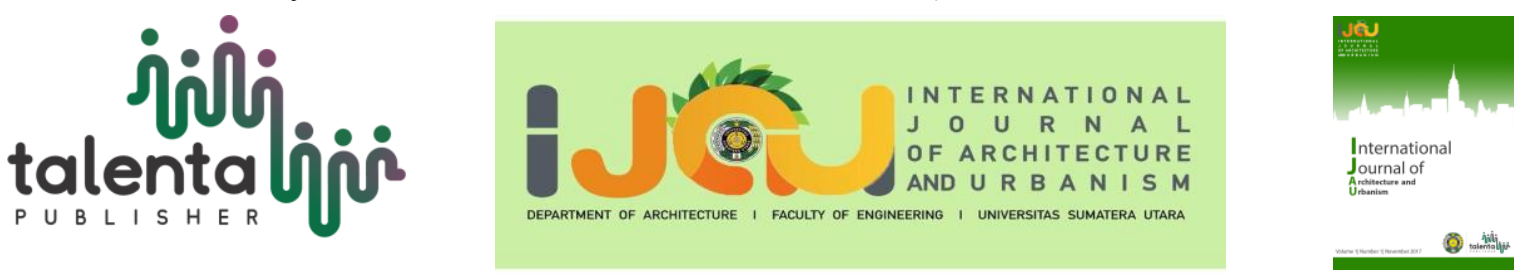

\title{
Determination of shear support capacity of transfer beam with varied section
}

\author{
Il-Ju Ri ${ }^{1 *}$, Song-Hyon Han ${ }^{1}$ \\ ${ }^{1}$ Pyongyang University of Architecture, DPRK
}

\begin{abstract}
In the RC structure with transfer beam, if the beam is fixed with the column under the transfer layer, it will cause very big reaction of the support at the supporting point and can cause the serious breaking because the section of the transfer beam is very big. It's not easy to make the section big for the whole length, so I studied about how to applicate the transfer beam with varied section to increase the capacity by changing the section of the beam around the supporting point. In this thesis, I suggested the formulars of the shear capacity of transfer beam with varied section by using the program ABAQUS
\end{abstract}

Keyword:transfer, beam, section, shear, capacity

Received 12 July 2021|Revised 22 August 2021 | Accepted 26 August 2021

\section{Introduction}

There are two types of transfer beams. One is below convexed transfer beam, and another one is the haunched transfer beam (Figure 1). Generally, the section of transfer beam is very big and the column under the transfer layer is relatively weak, and the linear stiffness of the beam is much bigger than the one of the wall in the structure with transfer beam [1-2]. If the transfer beam is fixed with the column under the transfer layer, there can be very big outer face bending moment in the bearing wall and can exceed the bending moment of the bearing wall. It can cause the crack and breaking on the bearing wall. The beam end bending moment can be lowered in the way of hinge joint between the transfer beam and the column below. In general making the end of the beam section small can resolve the pin structure.

This caused the below convexed transfer beam. Such below convexed transfer beam can effectively reduce the beam end bending moment but the bending moment at the span of the beam can be increased. In this thesis[6-7], if the opening in the frame-supported shear wall is near the supporting point of the transfer beam or if the shear capacity of the transfer beam is not enough,

\footnotetext{
*Corresponding author at:Taedonggang Dong, Taedonggang District, Pyongyang, DPRK

E-mail address: shypinguo202131@yeah.net
} 
haunch have to be installed in the supporting point of the transfer beam.

In this thesis [8], through the experiment of the structure of the transfer beam with haunch, I proved that the structure of the transfer beam with haunch not only effectively prevent the excess of the stiffness of the transfer beam by reducing the section of the beam but also prevent the creation of the "stronger columns and weaker beams"mechanism. I also proved that the structure with haunch is "stronger columns, weaker beams and even stronger joints"structure and the seismic performance is good. After the crack appeared in the wall beam with haunch, it slowly worked as arch and the bearing structure was similar to the "tie- arch" of the beam with constant section. The transfer beam of which the height of the section at the supporting point $h_{s}$ is higher than the height of the section at the center of span $h$ is called transfer structure with haunch.

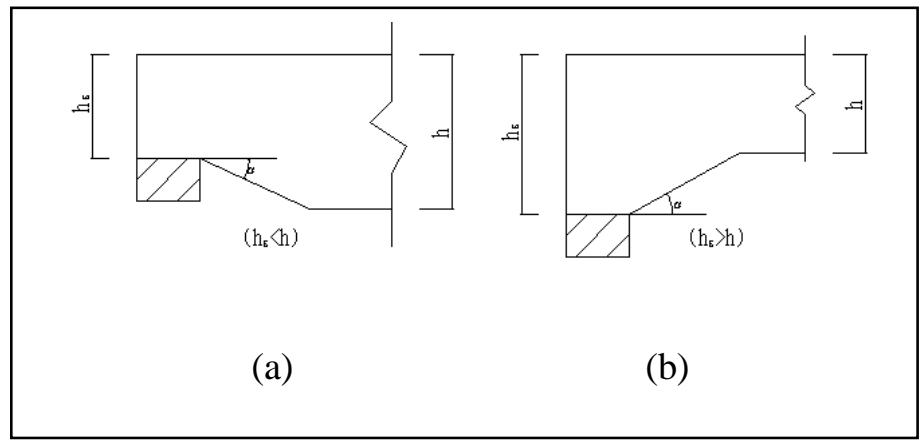

Figure 1. Transfer beam with varied section

(a) below convexed transfer beam, (b) transfer beam with haunch

The work performance and design method of the transfer beam with varied section is different from the transfer beam with constant section because the characteristics of the sections are different and below convexed transfer beam and the transfer beam with haunch has got various characteristics.

\section{The Calculation of Shear Capacity of Sloping Section}

Transfer beam with varied section has got various sections in its span, so after the crack appears at the sloping section, the "tie-arch" bearing structure has different characteristics from the transfer beam with constant section. Because of that, according to each bearing structure, the formulars of shear capacity of two types of transfer beams with varied section is determined. The main factors affect the shear capacity of the transfer beam of varied section are section size, pressure strength of concrete, shear-spane ratio, the rebar ratio of longitudinal rebar and horizontal distribute rebar and so on.

\subsection{Below convexed transfer beam}

To determine the formular of shear capacity according to the bearing characteristics of the below convexed transfer beam, the finite element analysis about the calculation model is done. Analysis is done with the finite element analysis program ABAQUS. The diameter of the cross 
reinforcement is $\emptyset 10$ and concrete grade is C30. Other features are as Figure 2. The shear capacity of the below convexed transfer beam is calculated on the 10 various analysis points from the supporting point to the center of span (Figure 3-Figure 12).

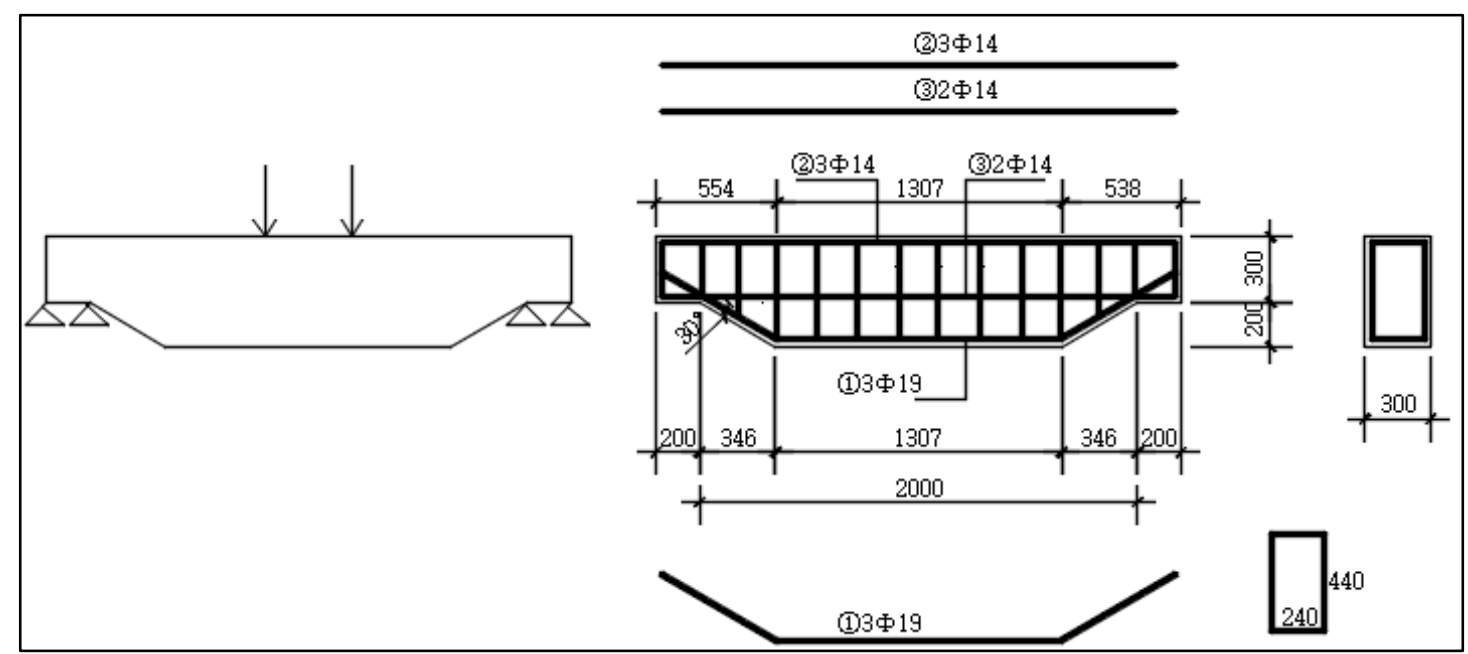

Figure 2. Geometric size and test positions of analysis model

The shear capacity of rebar and concrete decrease as the testing point is moving from the supporting point to the center as the fig 13. But as you can see, change ratio of concrete is not so big.

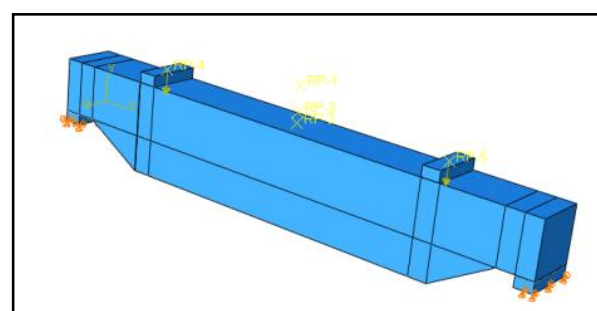

(a) calculation model

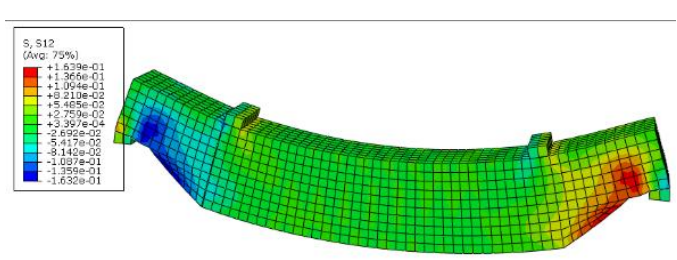

(b) stress of concrete

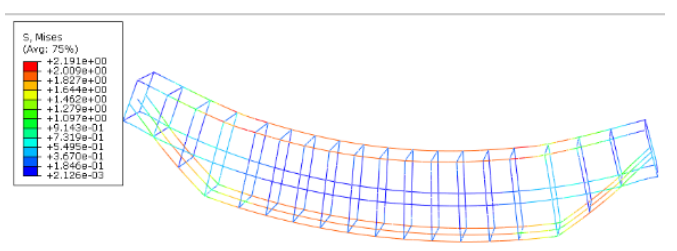

(c) stress of rebar

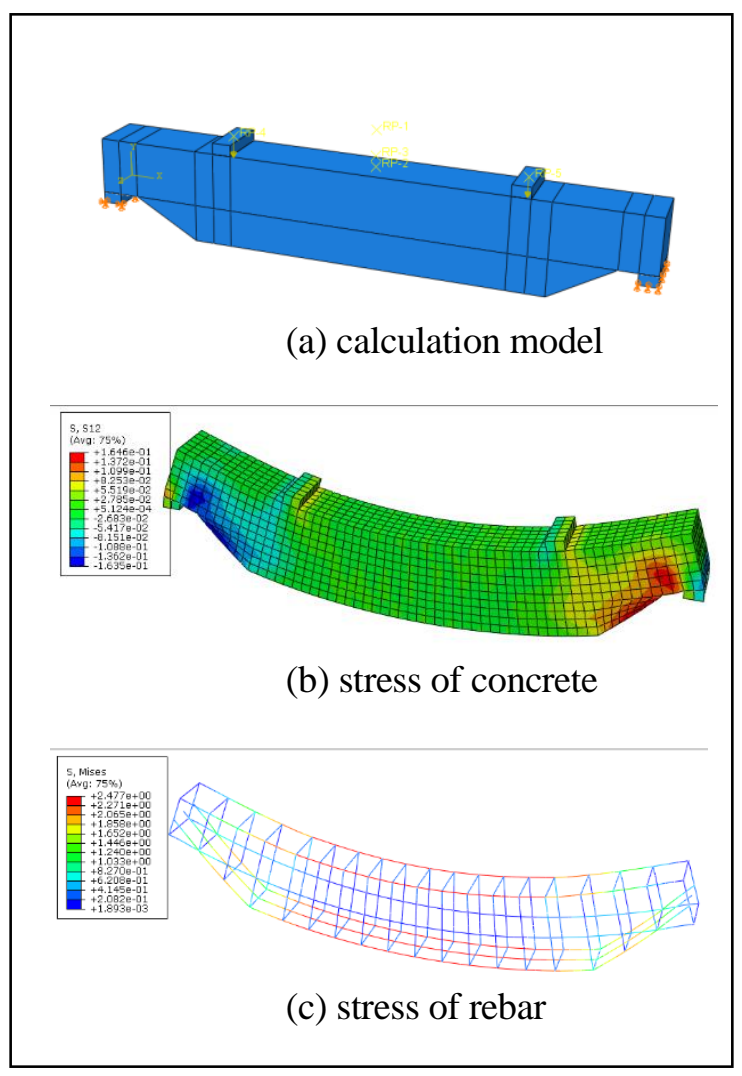

Figure 4. Analysis of model 2

Figure 3. Analysis result of model 1 


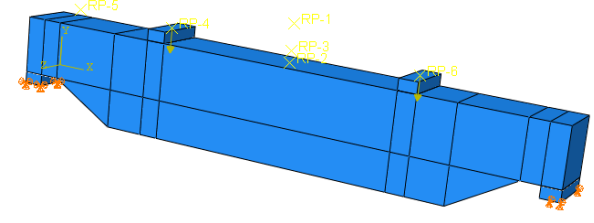

(a) calculation model

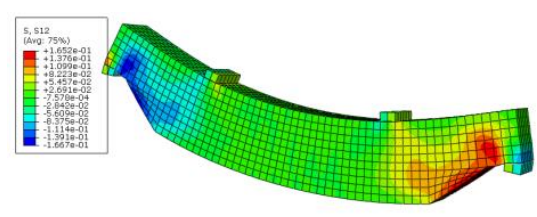

(b) stress of concrete

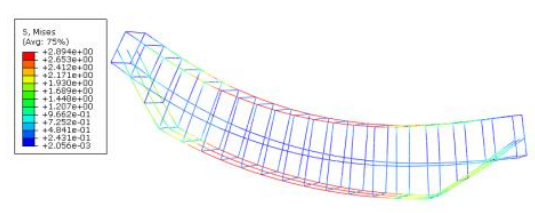

(c) stress of rebar

Figure 5. Analysis result of model 3

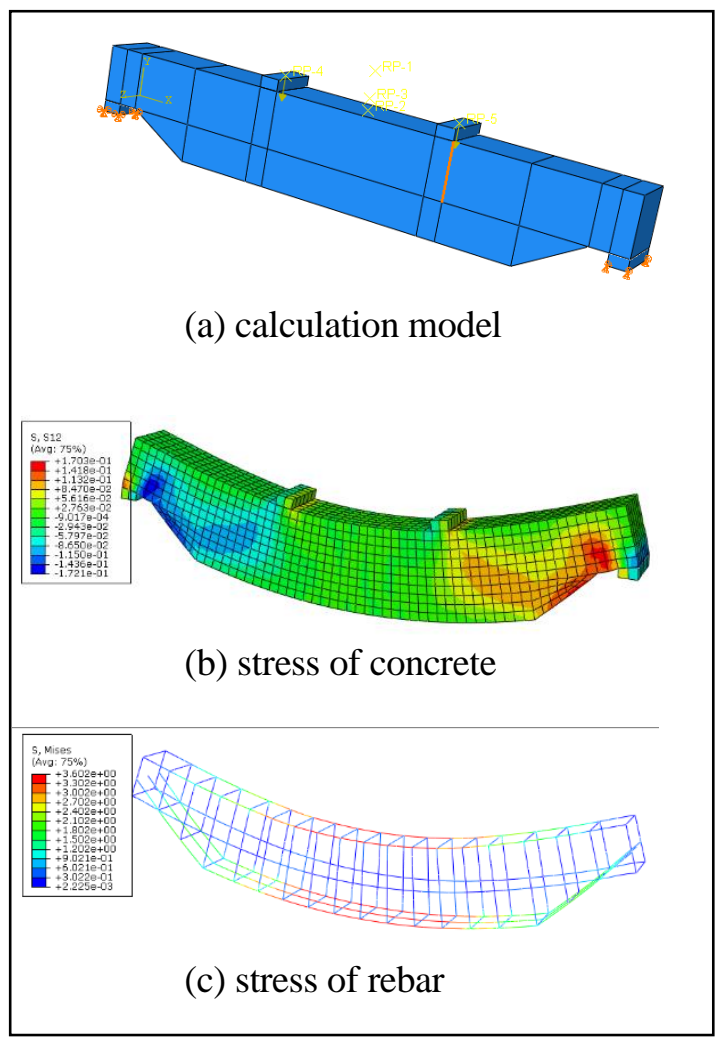

Figure 7. Analysis result of model 5

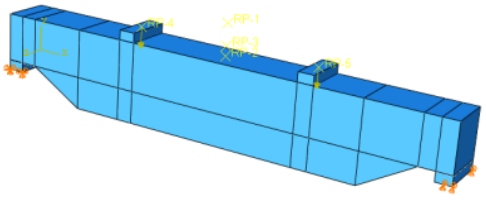

(a) calculation model

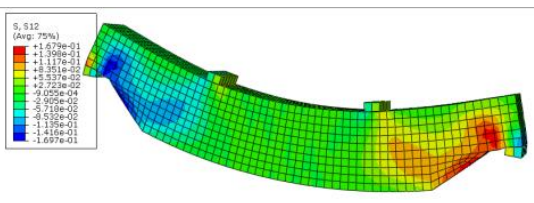

(b) stress of concrete

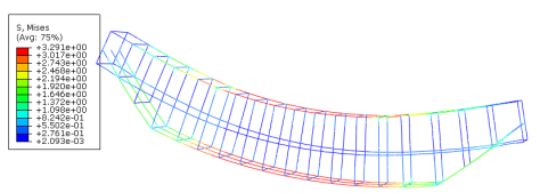

(c) stress of rebar

Figure 6. Analysis result of model 4

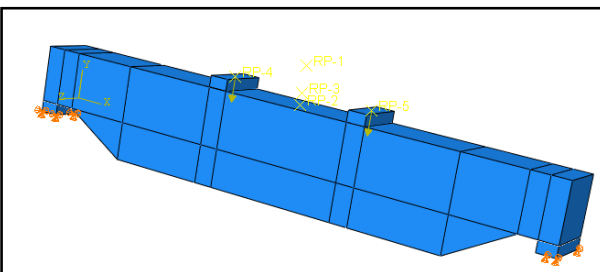

(a) calculation model

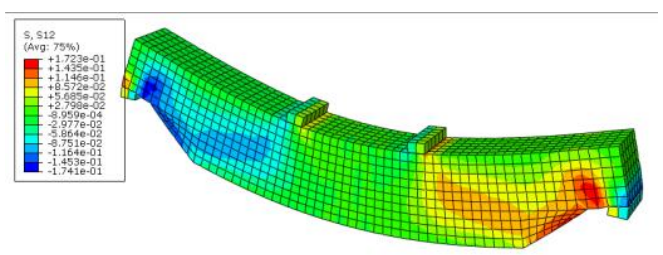

(b) stress of concrete

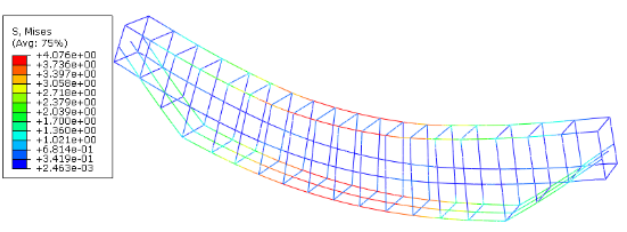

(c) stress of rebar

Figure 8. Analysis result of model 6 


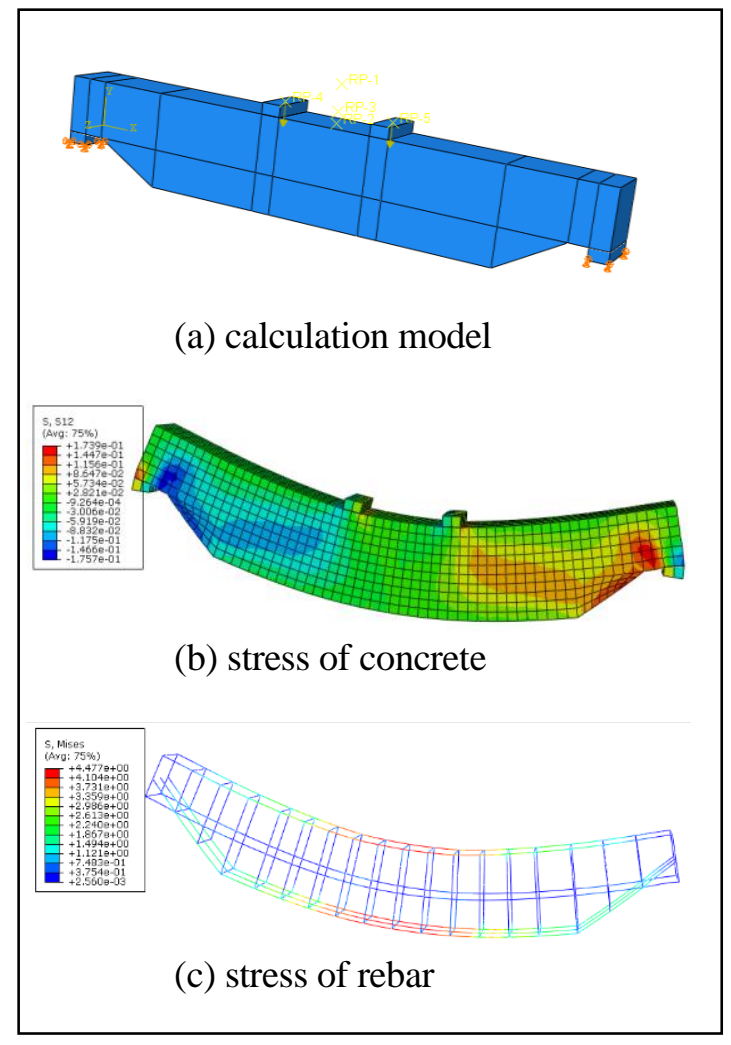

Figure 9. Analysis result of model 7

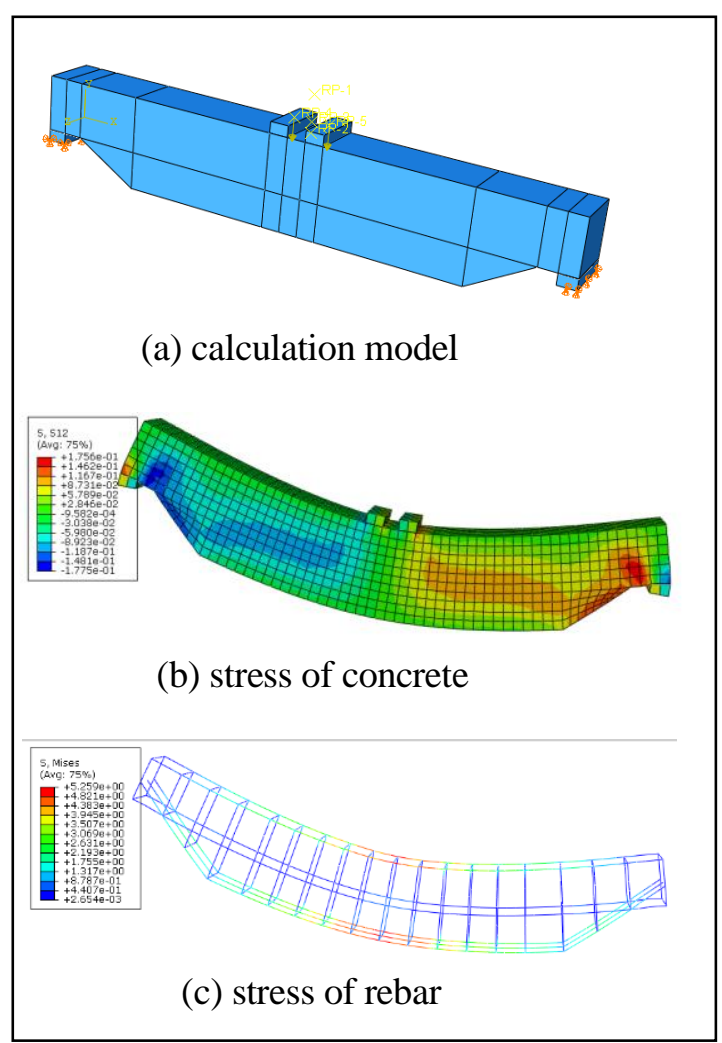

Figure 11. Analysis result of model 9

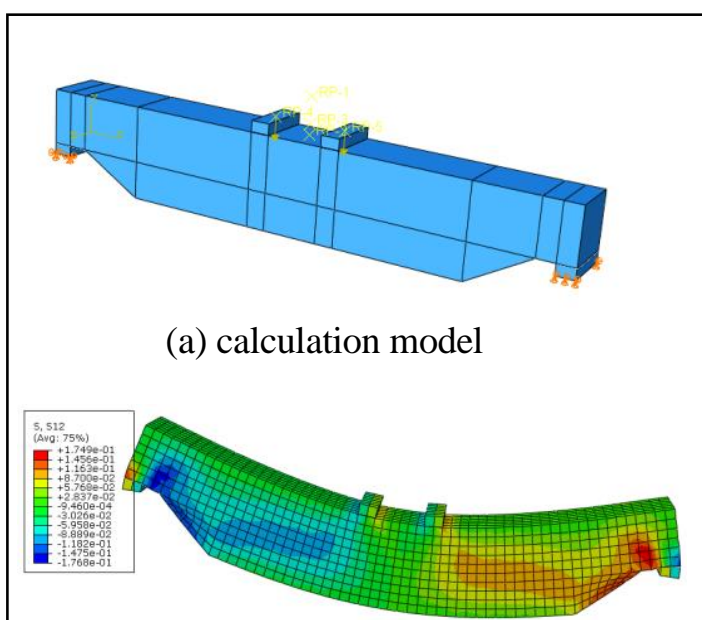

(b) stress of concrete

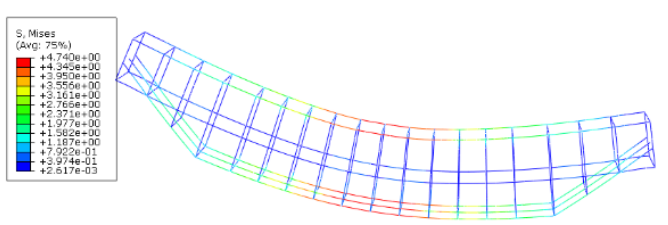

(c) stress of rebar

Figure 10. Analysis result of model 8

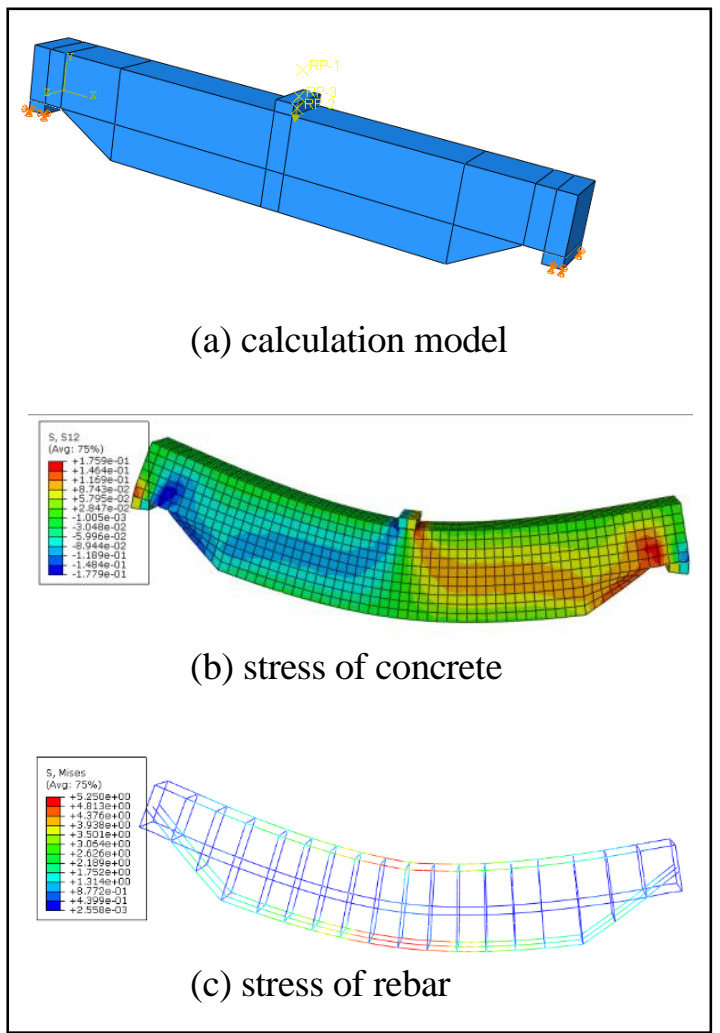

Figure 12. Analysis result of model 10 


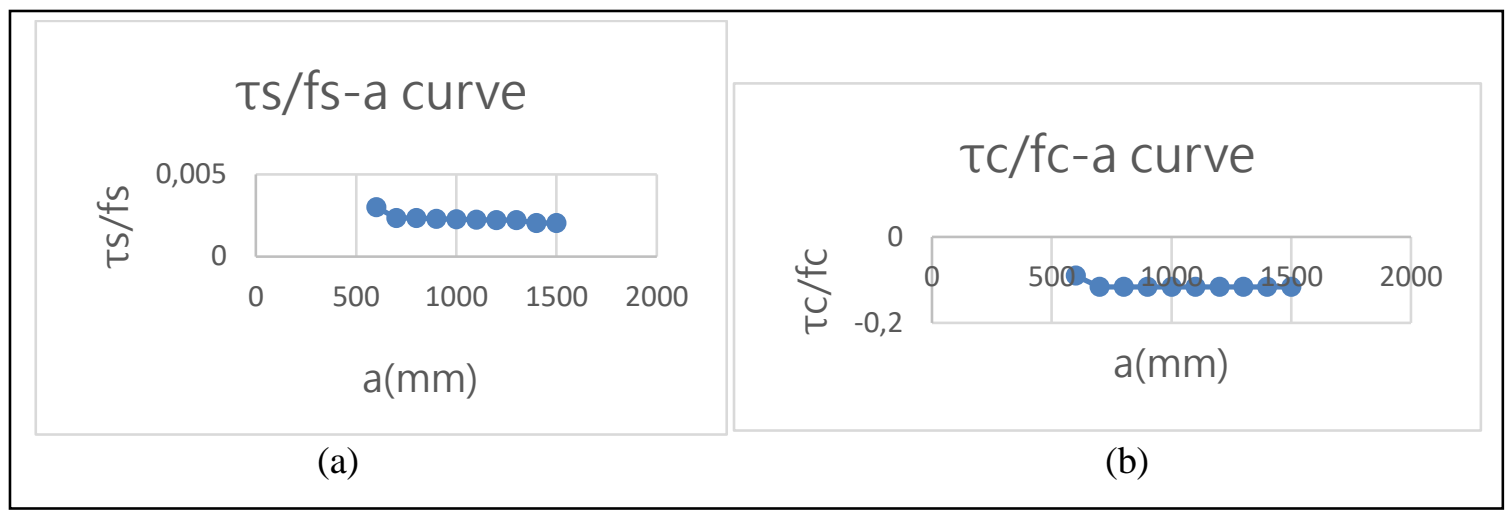

Figure 13. Stress curve of each calculation model

(a) shear stress curve of rebar, (b) shear stress curve of concrete

From the upper experiment you can get as follows:

$$
\begin{gathered}
V_{u}=V_{c s}+V_{s} \\
V_{c s}=\frac{0.81\left[1+22\left(\mu \cos a+\mu_{s h}\right)\right]}{1+\left(a / h_{s}\right)^{1.25}}\left(\frac{2 l_{s}}{h+h_{s}}\right) f_{c} b h_{s} \\
V_{s}=\frac{M-\mu_{s h} b h f_{s}\left(z-h_{s} / 2\right)}{c+z c t g a} \\
V_{s} \leq A_{s} f_{s} \sin a
\end{gathered}
$$

where $V_{c s}$-shear force that affects concrete and horizontal distribuite rebar which contains the curved rebar inside the concrete.

$V_{s}$-vertical component of resultant force of curved rebar

$z$-distance from horizontal component of curved rebar to the compression part of sloping section. $z=0.8 h_{s}$

$c$-distance from inner point of the support to the $V_{c s}$ reaction line, $c=a-l_{s} / 2 \leq 0.8 h$ for concentrated load and $c=0.8 h_{s}$ for distributed load.

$A_{s}$-area of curved rebar

$l_{s}$-length of the base plate

$M$-bending moment of the end of sloping section

In case the shear span ratio and supporting length are not considered the calculation can be simple.

$$
V_{u}=V_{c s}+V_{s}
$$




$$
\begin{gathered}
V_{c s}=0.12\left[1+22\left(\mu \cos a+\mu_{s h}\right)\right] f_{c} b h_{s} \\
V_{s}=\frac{M-0.2 \mu_{s h} b h_{s}^{2} f_{s}}{c+0.9 h_{s} c t g a} \\
V_{s} \leq 0.7 A_{s} f_{s} \sin a
\end{gathered}
$$

Comparing the calculation result and experimentation result is as follows.

$\mu=1.03, \delta=0.098$ in equation 1 and $\mu=1.44, \delta=0.187$ in equation $1-1$.

\subsection{Transfer beam with haunch}

To determine the formular of the shear capacity of the transfer beam with haunch, the finite element analysis about the calculation model as follows (Figure 14).

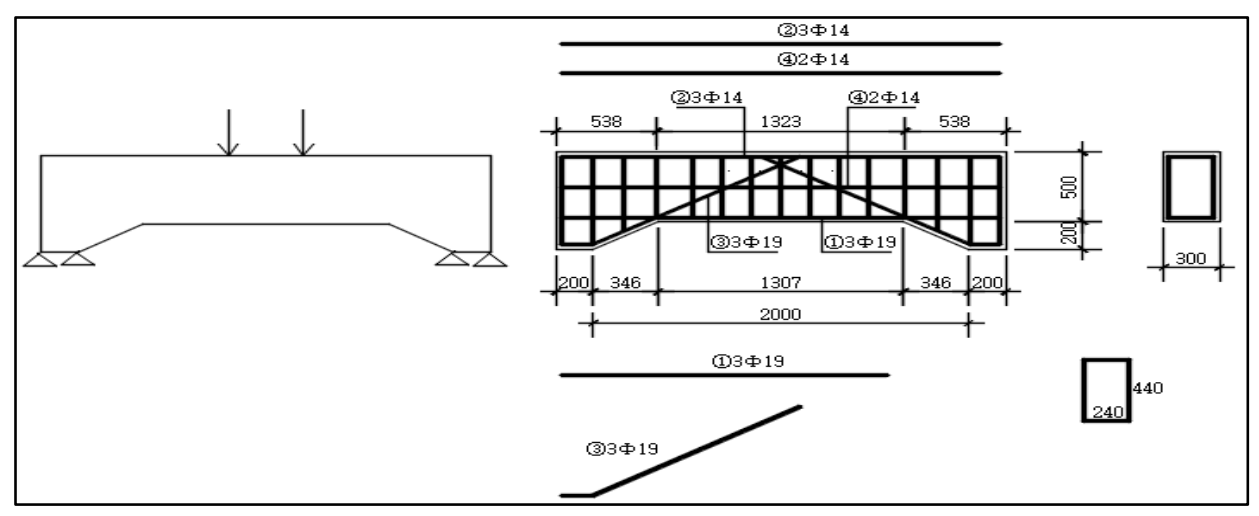

Figure 14. Geometric size and test point of analysis model

As you can see in the analysis result, there is one concrete compression part in "tie-arch"of transfer beam with haunch and increases the section of the arch and so does shear capacity. The change of section height can be considered by using the factor $h_{s} / h$ from the formular of the shear capacity (Figure 15-25). 


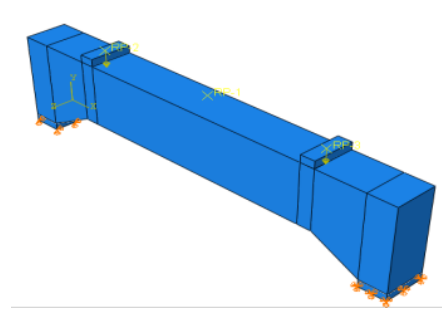

(a) calculation model

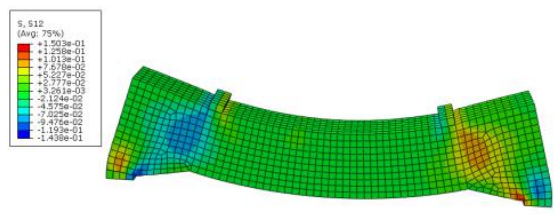

(b) stress of concrete

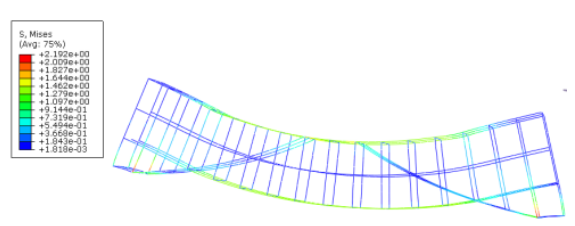

(c) stress of rebar

Figure 15. Analysis result of model 1

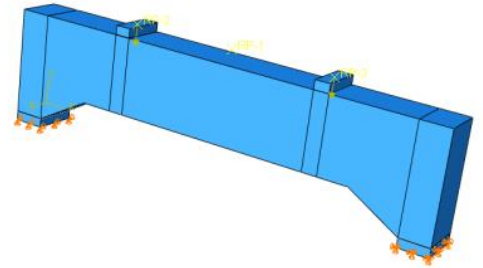

(a) calculation model

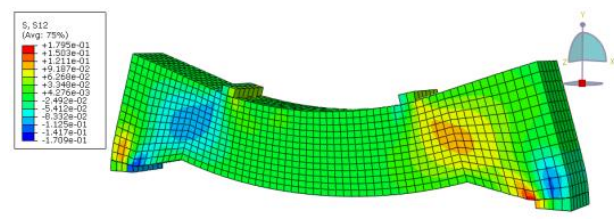

(b) stress of concrete

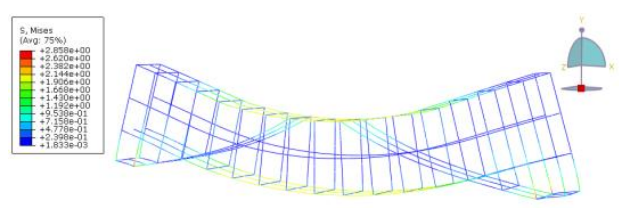

(c) stress of rebar

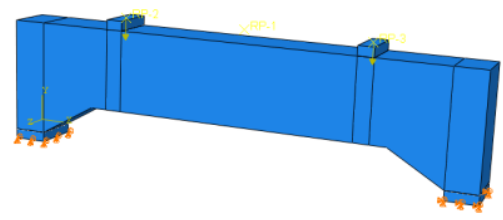

(a) calculation model

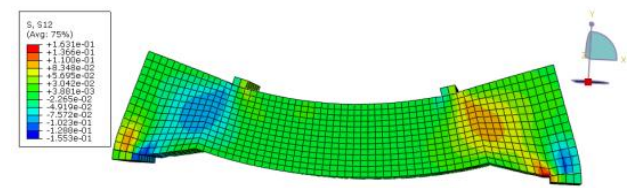

(b) stress of concrete

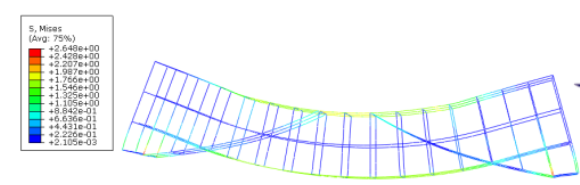

(c) stress of rebar

Figure 16. Analysis result of model 2

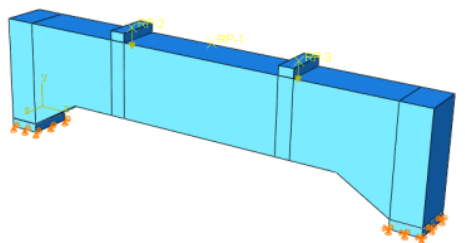

(a) calculation model

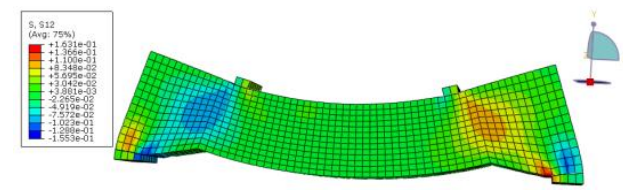

(b) stress of concrete

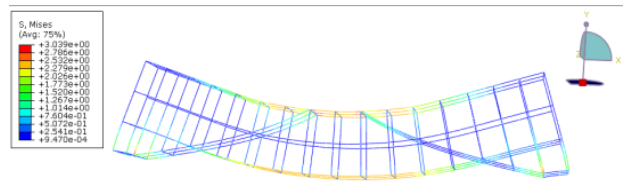

(c) stress of rebar

Figure 18. Analysis result of model 4

Figure 17. Analysis result of model 3 


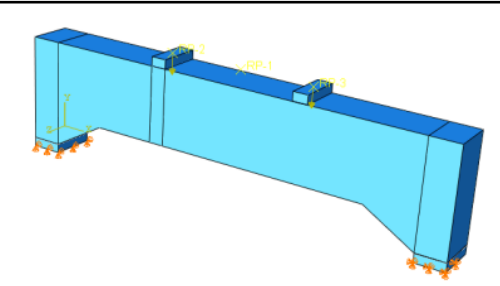

(a) calculation model

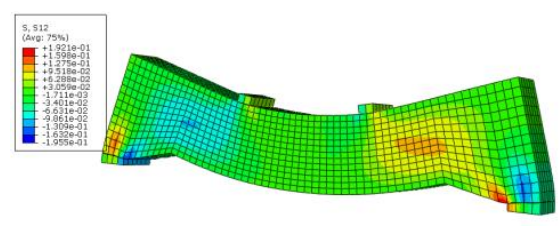

(b) stress of concrete

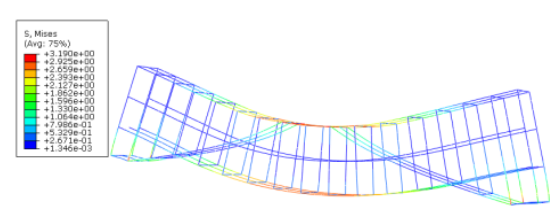

(c) stress of rebar

Figure 19. Analysis result of model 5

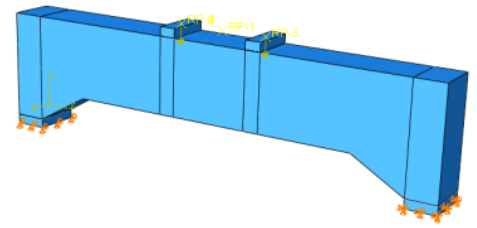

(a) calculation model

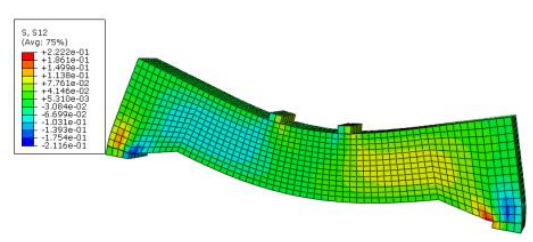

(b) stress of concrete

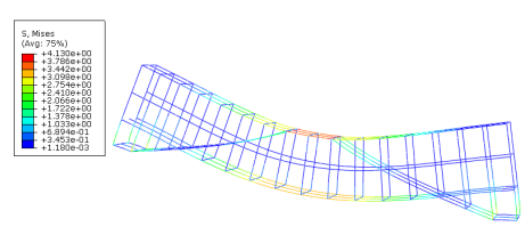

(c) stress of rebar

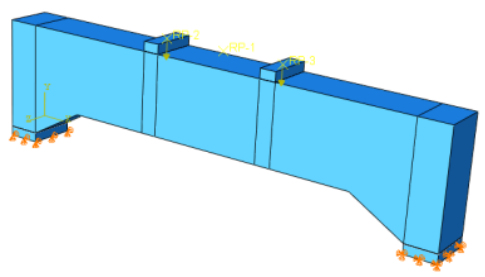

(a) calculation model

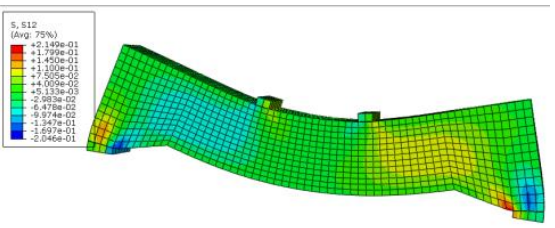

(b) stress of concrete

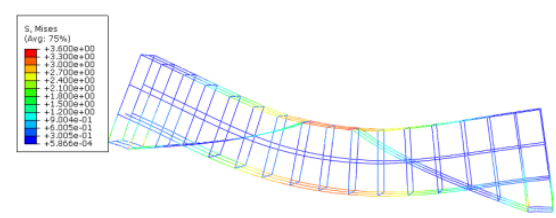

(c) stress of rebar

Figure 20. Analysis result of model 6

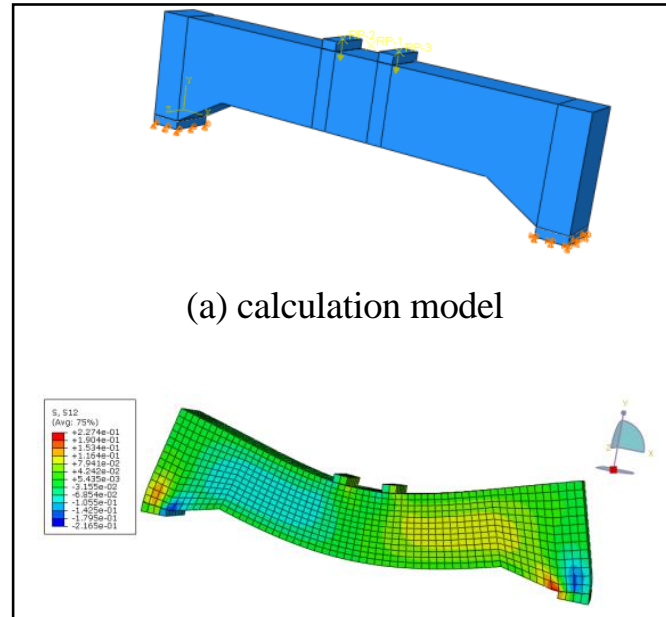

(b) stress of concrete

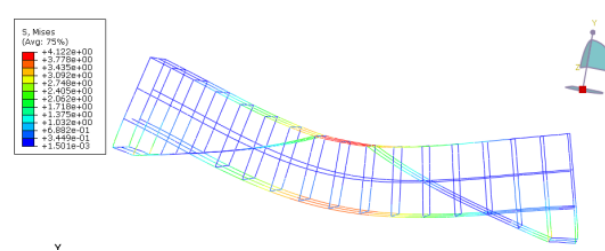

(c) stress of rebar

Figure 22. Analysis result of model 8

Figure 21. Analysis result of model 7 


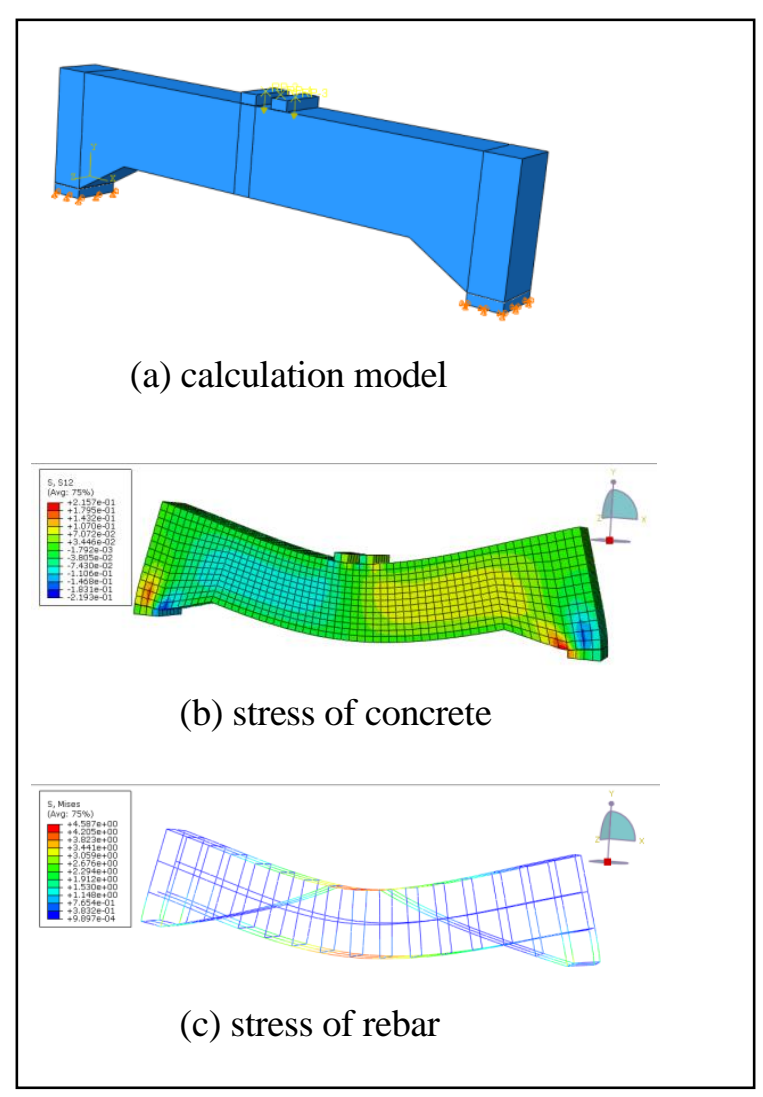

Figure 23. Analysis result of model 9

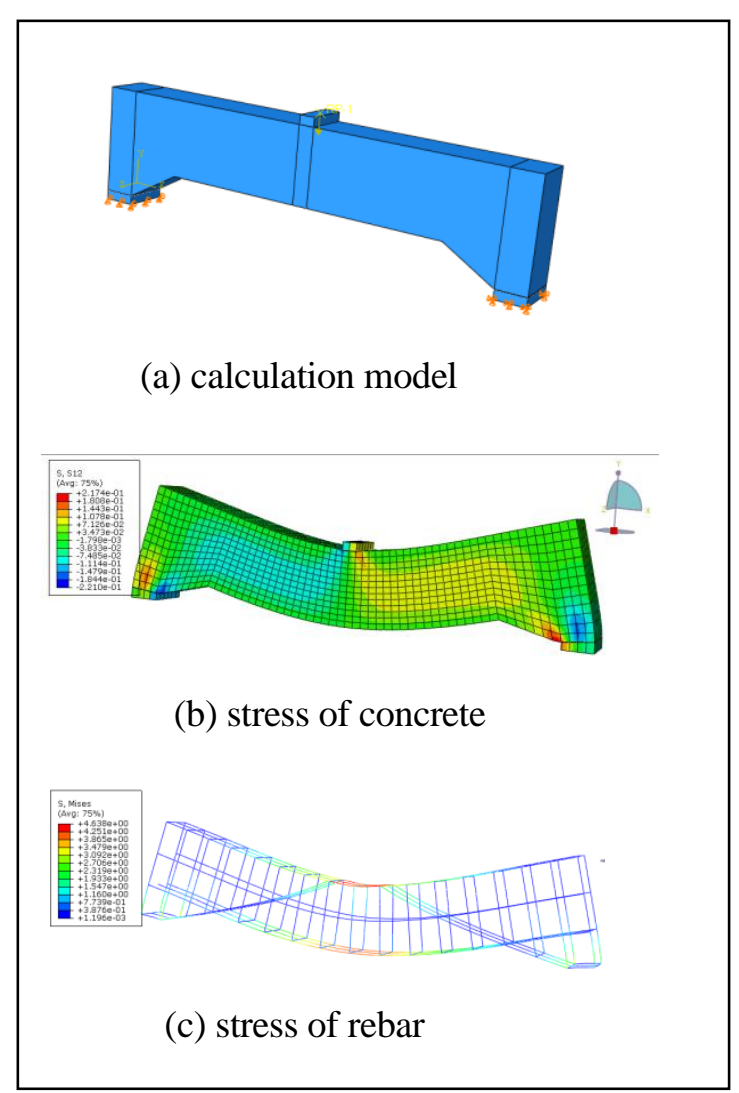

Figure 24. Analysis result of model 10

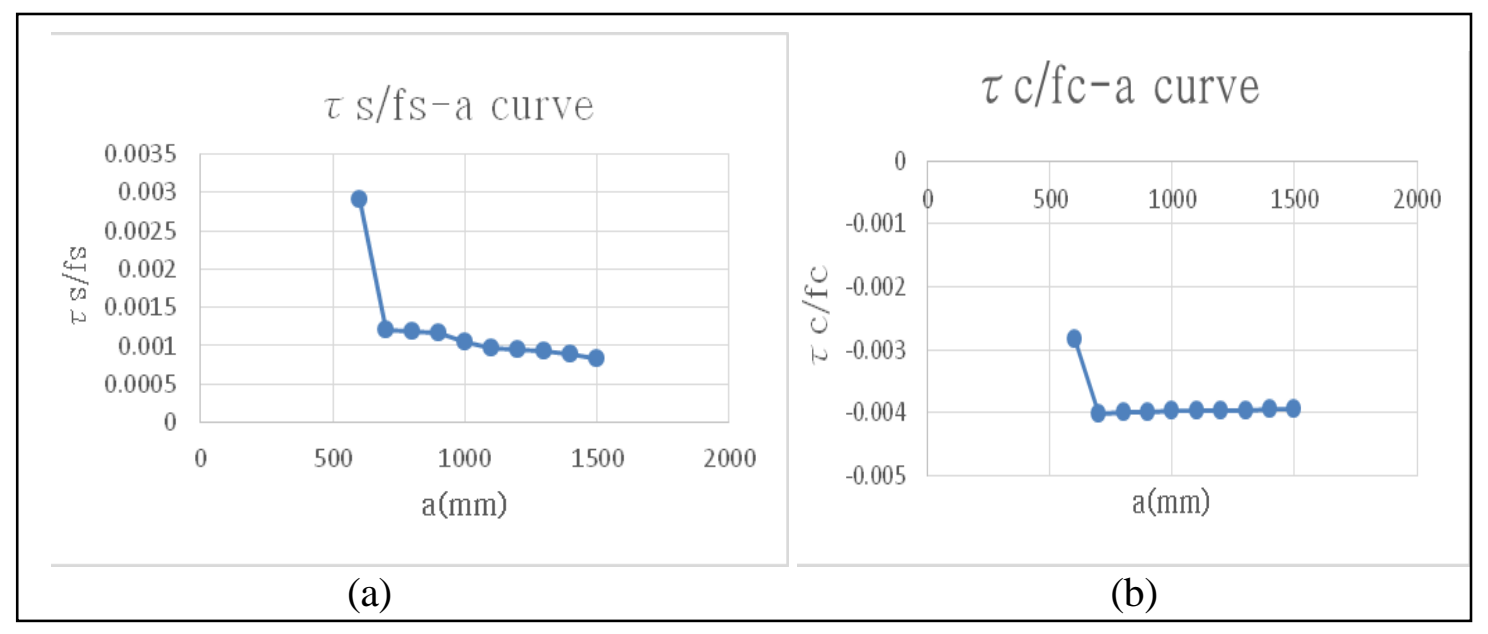

Figure 25. Stress curve of each calculation model

(a) shear stress curve of rebar, (b) shear stress curve of concrete

From the upper experiment you can get as follows:

$$
V_{u}=\frac{0.203\left[7 h_{s} / h+88\left(\mu+\mu_{s h}\right)-3\right]}{1+\left(a / h_{s}\right)^{1.25}}\left(\frac{l_{s}}{h_{s}}\right)^{0.75} f_{c} b h
$$


By sampling the equ. 8 you can get as follows:

$$
V_{u}=0.03\left[7 h_{s} / h+88\left(\mu+\mu_{s h}\right)-3\right] f_{c} b h_{s}
$$

Comparing the experimentation result and calculation result of the shear capacity of the transfer beam with hauch is as follows:

$$
\mu=1.01, \delta=0.079 \text { in equation } 8 \text { and } \mu=1.62, \delta=0.150 \text { in equation } 9 .
$$

\section{3 calculation of shear capacity of transfer beam with varied section}

Generalizing upper formulars of shear capacity of two kinds of transfer beam with varied section, one formular of shear capacity of transfer beam can be come by.

$$
V_{u}=0.12\left[7 \eta+22\left(\mu+\mu_{s h}\right)\right] f_{c} b h
$$

where $\eta$-correction factor of shear capacity.

-below convexed transfer beam:

$$
\eta=h_{s} / h+25 \mu \sin a \text { 또는 } \eta \leq 1
$$

-transfer beam with hauch: $\quad \eta=1.25 h_{s} / h-0.25$

-transfer beam with constant section: $\quad \eta=1.0$

Comparing the experimentation result and calculation result of the shear capacity is as follows:

$n=19, \mu=2.46, \delta=0.277$ for below convexed transfer beam and $n=12, \mu=1.76, \delta=0.142$ for the transfer beam with hauch.(where $n$-number of element $\mu$-average value, $\delta$-average standard deviation)

\section{Crack check of sloping section}

The formular of crack check of sloping section of the transfer beam with varied section is as follows:

$$
V_{c}=\frac{1.02}{0.55+\lambda} f_{c t} b h
$$

When the height of section is the same as the height of section on the center span and the shear span ratio is $\lambda=a / h$, comparing the experiment result and the calculation result of the transfer 
beam with varied section is as follows.

$$
\begin{aligned}
& n=19, \mu=1.67, \delta=0.213 \text { for below convexed transfer beam and } \\
& n=12, \mu=1.47, \delta=0.166 \text { for transfer beam with hauch. }
\end{aligned}
$$

As you can see, in case of the transfer beam with varied section, the height of section can be assumed as the height on the span center to check the crack of the sloping section.

\section{Concluding remarks}

In this thesis, the finite element analysis about the transfer beam with varied section are done and concluded as follows. First, the shear stress of rebar and concrete get decrease as the test point goes far from the supporting point in the below convexed transfer beam. But the change of concrete is not so big. Then, there is only one compression part between the bottom of arch and ths supporting point in "tie-arch" bearing structure of transfer beam with haunch and increases the section of the arch and so does shear capacity.

\section{REFERENCES}

[1] Wolfgang Schueller. High Rise Building Structures. John wiley and sons publishing, London, 1978.

[2] Xi-an Zhao. The tall building structural practical design method. Shanghai: Tongji University Press, 1991. (in Chinese)

[3] Xing-rong Tang, Ruo-quan He. High-rise buildings in the conversion layer structure of the current situation and development. Journal of Suzhou Institue of Urban Construction and Environmental Protection, 2001,14(3):1-8. (in Chinese)

[4] Xing-rong Tang. Conversion of the High-rise building design and construction. Beijing:China Architecture \& Building Press,2002. (in Chinese)

[5] Chinese Specification. Specification for seismic test method (JGJ 101 - 96). Beijing: China Construction Industry Press,(1997). (In Chinese)

[6] Tsang HH, Wilson JL, Lam NTK. A refined design spectrum model for regions of lower seismicity. Aust J Struct Eng 2017;18:3-10.https://doi.org/10.1080/ 13287982.2017.1297529.

[7] Wibowo A, Wilson JL, Lam NTK, Gad EF. Drift performance of lightly reinforced $\begin{array}{llll}\text { concrete } & \text { columns. } & \text { Eng } & \text { Struct }\end{array}$ 35.https://doi.org/10.1016/j.engstruct.2013.11.016. 
[8] Arturo T, Luis Angel U. Cyclic behavior of continuous reinforced concrete haunched beams with transverse reinforcement designed to fail in shear

[9] ACI-318-14, Building Code Requirements for Structural Concrete (ACI-318-11) and Commentary (ACI 318R-14), American Concrete Institute, Farmington Hills, Michigan, USA, 2014. 